have found their contact with psychiatric services useful, but I find that I need to let go of the desire to solve all their problems or offer them a way of escaping all their difficulties. This is how it is with mental illness generally. I believe we need to be more realistic about what we can offer our patients in terms of 'recovery' while at the same time always working with them to alleviate their difficulties in the hope that things will improve.

Jon Goldin, Specialist Registrar Child and Adolescent Psychiatry, TheTavistock \& Portman NHS Trust, 120 Belview Lane, London NE3 5BA

\section{Community Treatment Orders}

Sir: Two recent articles (Psychiatric Bulletin, November 1999, 23, 644-646 and Psychiatric Bulletin, November 1999, 23, 647-648) continue the debate surrounding the proposed introduction of Community Treatment Orders (CTOs). Having experience in the use of CTOs in Victoria, Australia it is our contention that a CTO does not confer any advantage to the patient in comparison with a comprehensive community care. Indeed, we observed that their use frequently served to alienate patients from mental health services.

In reviewing CTO usage Mclvor (1998) highlights the paucity of research in this area despite their widespread implementation in Australia and New Zealand and suggests the need for controlled trials in order to justify their continued use. Burns poses the question, 'is there a group of patients who are poorly served by the present legislation who are currently repeatedly subject to compulsory admission and whose welfare would be better served by a CTO?'. In our endeavour to practise evidence-based psychiatry surely the question must be, 'Can a patient be subject to a CTO in the absence of proven efficacy?'.

\section{Reference}

MCIVOR, R. (1998) The community treatment order: clinical and ethical issues. Australian and New Zealand Journal of Psychiatry, 32, 223-228.

*Feargal Leonard, Specialist Registrar in Old Age Psychiatry, Priority House, Hemitage Lane, Maidstone, Kent ME16 9PH， Michael Ventress Senior House Officer in Forensic Psychiatry, Trevor Gibbens Unit, Maidstone

Sir: I think Professor Burns (Psychiatric Bulletin, November 1999, 23,647-648) is quite right to point out that most psychiatrists can think of 'a handful' of patients who would truly benefit from a Community Treatment Order (CTO). The criticism though that Moncrieff \& Smyth are posing the wrong question (Psychiatric Bulletin, November 1999, 23, 644-646) "How can psychiatry control antisocial behaviour?" is slightly unfair. The genesis of the currently proposed reforms can be traced back to Frank Dobson's widely publicised comments on the Michael Stone case, that community care had failed because psychiatrists had not been using their power to treat people in the community. Of course psychiatry possessed no such power at the time of Mr Dobson's ill-informed comments, but Mr Dobson never retracted this statement and the government has gone on to propose CTOs. College caveats aside, it is, therefore, correct to view the CTO as the Government's attempt to hold psychiatrists accountable for the behaviour of dangerous people who have had contact with psychiatric services

Andrew Al-Adwani, Locum Consultant Psychiatrist, Department of Psychiatry, Scunthorpe Genera Hospital, Cliff Gardens, Scunthorpe, North Lincolnshire DN15 7BH

Sir: I write regarding the two articles on Community Treatment Orders by

Moncrieff \& Smyth and Burns (Psychiatric Bulletin, November 1999, 23, 644-646 and 647-648)

My concern is that occasionally a patient who stops his or her antipsychotic medication, against advice, remains well for some years at least.

I know of no way to predict this. Thus, some people may be forced indefinitely to take medication they do not need.

Robert J. Doig, Consultant Psychiatrist, St Ann's Hospital, St Ann's Road, London N15 3TH

\section{Mobile telecommunications and agoraphobia - a modern treatment advance?}

Sir: I wish to report how the advent of new technologies may be influencing the ways in which patients manage their own symptoms.

It recently came to my attention that a husband and wife had devised a method by which they had been able to extend the period of time in which a profoundly agoraphobic patient was able to be independent of their spouse, both inside and outside the home. By both parties of the marriage having a mobile telephone in their possession it allowed, in this case the husband affected with a considerable degree of agoraphobia, to spend considerable periods of time on his own without developing a severe degree of anxiety and fearfulness, with accompanying panic symptoms and an urge to either return home or seek the company of his wife. There is, therefore, an increased degree of security knowing that help is at hand if symptoms recur. An example of this is that he is now able to spend long periods of time fishing, away from the home, an activity he found intolerably stressful previously, as he became acutely concerned if he was not able to return home immediately, or did not have access to a means of transport to do so. Therefore, his anticipatory anxiety has been alleviated by the knowledge that he can contact his wife at any time, leading to a larger social repertoire. He developed a much better sense of control over his circumstances and has broken the cycle of dread of being alone in public places. While there are obviously dangers of dependency occurring because of this, I do feel it allows the patient to have more autonomy.

I am unaware of any other reports of mobile telecommunications being used in this way and it provides a good example of how new technologies may have serendipitous spin-offs for psychiatric patients.

John W. Coates, Consultant Psychiatrist, Mental Health Services, Rotherham General Hospital, Moorgate Road, Rotherham, South Yorkshire S60 2UD

\section{A minister for adolescence?}

Sir: We were encouraged to read Parkin's (Psychiatric Bulletin, October 1999, 23, 587-589) review of the difficulties surrounding the admission and treatment of 16- and 17-year-olds under the Mental Health Act 1983. As a newly formed Community Adolescent Mental Health Team we have been grappling with the current legal confusion surrounding the status of adolescents on a daily basis. The concept of Gillick competence developed from a case regarding the rights of those under 16 to seek confidential contraceptive advice and, as such, it made sense but it is now being extended into areas where it is increasingly nonsensical and legally untested, for example, should the parents of a cannabis-using 16 -year-old be told about the drug use?

The confusion over adolescents' legal status appears to hinge on one issue: are rights acquired on reaching a certain age or a certain competence? The answer at the moment is 'it depends'. It depends on whether the issue in question is consent to sex or treatment, whether the patient is male or female, homosexual or heterosexual and consenting or refusing. Adolescents' legal rights should surely be either gained at a certain age, or based on their individual competence, but not the current mixture. 